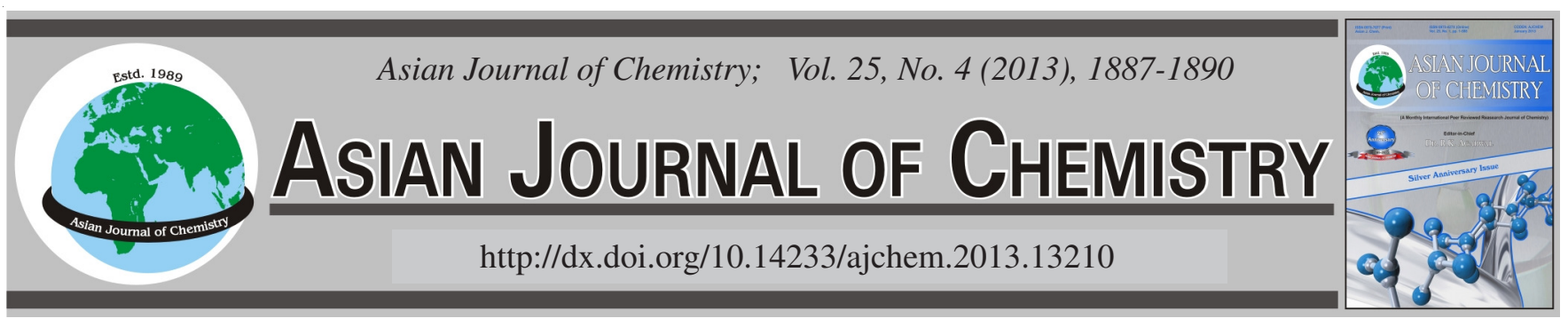

\title{
Indirect Spectrophotometric Determination of Tolterodine Tartrate in Pure and Pharmaceutical Preparations
}

\author{
SafWAn M. Fraihat ${ }^{1, *}$ and Hatem S. KhatiB ${ }^{2}$
}

${ }^{1}$ Hamdi Mango Center for Scientific Research, Jordan University, Amman 11942, Jordan

${ }^{2}$ College of Pharmacy, University of Jordan, Amman 11942, Jordan

*Corresponding author: E-mail: s.fraihat@ju.edu.jo

(Received: 9 December 2011;

Accepted: 8 October 2012)

AJC-12243

\begin{abstract}
Two simple, accurate, sensitive and economical procedures for the estimation of tolterodine tartrate (TOL) both in pure and in pharmaceutical formulations have been developed. The first method (A) was based on the oxidation of the studied drug by a known excess of cerium(IV) as an oxidizing agent and subsequent determination of unreacted oxidant by reacting it with (methylene blue) dye, while the second method (B) involved N-bromosuccinimide (NBS) as an oxidant and (indigo) dye. The absorbance values were determined at 660 and 610 $\mathrm{nm}$, respectively. The reacted oxidant corresponds to the drug content. Regression analysis of Beer-Lambert plots showed good correlations in the concentration ranges 5-18 and 38-80 $\mu \mathrm{g} / \mathrm{mL}$ for methods $\mathbf{A}$ and $\mathbf{B}$, respectively. The molar absorptivity, Sandell sensitivity, detection | and quantification limits were calculated. The optimum reaction conditions and other analytical parameters were evaluated. The proposed methods were applied to the determination of tolterodine tartrate in pharmaceutical formulations. The results have demonstrated that the methods are equally accurate and reproducible as the official methods.
\end{abstract}

Key Words: Tolterodine tartrate, Spectrophotometry, Ce(IV), N-Bromosuccinimide, Pharmaceuticals.

\section{INTRODUCTION}

Tolterodine tartarate (TOL), (R)-2-[3-[bis(1-methylethyl)amino]-1-phenylpropyl]-4-methylphenol $\left[\mathrm{R}-\left(\mathrm{R}^{*}, \mathrm{R}^{*}\right)\right]-2,3-$ dihydroxybutanedioate (1:1) (salt) (Fig. 1) is a white, crystalline powder. The $\mathrm{pK}_{\mathrm{a}}$ value is 9.87 and the solubility in water is 12 $\mathrm{mg} / \mathrm{mL}$. It is soluble in methanol, slightly soluble in ethanol and practically insoluble in toluene.<smiles>Cc1ccc(O)c(C(CCN(C(C)C)C(C)C)c2ccccc2)c1</smiles>

Fig. 1. Chemical structure of tolterodine tartarate

Tolterodine tartarate is a muscarinic receptor antagonist indicated for the treatment of overactive bladder $(\mathrm{OAB})$ with symptoms of urge urinary incontinence, urgency and frequency.

Tolterodine tartarate was the first drug to be developed specifically for the treatment of overactive bladder. Since it was first introduced into the market in 1998 more than 10 million patients have been exposed to the drug ${ }^{1}$.
The first step in the development of a pharmaceutical product is the development and validation of an analytical procedure for the active pharmaceutical ingredient (API) under development.

Pharmaceutical samples, including those of dissolution, stability, quality control and bioavailability and bioequivalence studies, are generally vast in numbers and thus one of the most important characteristics of a successful analytical procedure for pharmaceutical development and manufacturing is the ability of the analytical method to lend itself easily to automation.

Several methods have been reported for the analysis of tolterodine tartrate, these include gas chromatography-mass spectrometry (GC-MS) ${ }^{2}$, capillary liquid chromatographytandem mass spectrometry ${ }^{3,4}$ and liquid chromatography-mass spectrometry (LC-MS) ${ }^{5-7}$. These methods rely on powerful MS detectors to reach limits of quantitation in the $\mathrm{pg} / \mathrm{mL}$ levels which is needed in the analysis of biological samples in pharmacokinetic studies.

Capillary electrophoresis has been reported as a method of analysis for tolterodine tartrate with the objective of achieving chiral separation of the active $R$ and inactive $S$ enatiomers of tolterodine tartrate and the quantitation of the $\mathrm{S}$ isomer as an impurity in active pharmaceutical ingredients of the R configuration $^{8,9}$. Enatiomeric separation has also been achieved by 
liquid chromatography with quantitation limits reaching 0.05 $\mu \mathrm{g} / \mathrm{mL}^{10,11}$.

Routine analysis of tolterodine tartrate in quality control and dissolution testing, responsible for most of the samples bulk, does not require such a low limit of quantitation or enantioseparation.

With the objective of catering to the needs of such routine analysis, a group of direct and derivative UV spectrophotometric methods have been reported for the analysis of tolterodine tartrate in bulk raw material form as well as in pharmaceutical dosage forms ${ }^{12-16}$. However, the limit of quantitation never reached below the $2.5 \mathrm{mg} / \mathrm{mL}$ level ${ }^{13}$. This level may be adequate for the assay of bulk active pharmaceutical ingredient but it is not suitable when attempting to evaluate the drug release where the dose of the drug (2-4 mg) is dissolved in $900 \mathrm{~mL}$ of dissolution medium and where the characterization of the early points of the release profile ( $\mathrm{ca} .10 \%$ of the complete release corresponding to $c a .2 \mu \mathrm{g} / \mathrm{mL}$ ) is needed.

As an alternative, different high performance liquid chromatography (HPLC) methods were developed using C8 columns and UV detection reaching a lower level of quantitation of $50 \mu \mathrm{g} / \mathrm{mL}^{17-19}$. This level is still far from our objective of $2 \mu \mathrm{g} / \mathrm{mL}$. In addition, the two HPLC methods use large quantities of acetonitrile (40 and $55 \%$ ) in the mobile phase suggesting an increased cost of the routine analysis considering the significant surge in the price of acetonitrile.

The solution of such a situation is the use of alternative procedures that does not use expensive methods that consume large amounts of chemicals.

We propose the development of simple spectrophotometric method for the determination of tolterodine tartrate in pure and pharmaceutical preparations as an alternative procedure for the more costly and demanding HPLC.

The proposed methods are based on treating the drug with excess amount of oxidizing agent either cerium(IV) sulphate or N-bromosuccinimide in acidic media then the excess oxidant decolorizes the colour of two different dyes (methylene blue) and (indigo) for methods $\mathbf{A}$ and $\mathbf{B}$, respectively. The absorbance values of the final solutions were measured at 660 and $610 \mathrm{~nm}$ and they correlate with the concentration of Tolterodine in the solution. The methods were applied for the determination the amount of Tolterodine in different pharmaceutical preparations.

\section{EXPERIMENTAL}

A double-beam optical system SpectroScan 80D UV-VIS spectrophotometer with spectral bandwidth of $2 \mathrm{~nm}$, wavelength accuracy $\pm 0.3 \mathrm{~nm}$ (with automatic wavelength correction), wavelength range (190-1100 $\mathrm{nm}$ ), wavelength reproducibility $\pm 0.2 \mathrm{~nm}$ and a pair of $1 \mathrm{~cm}$ matched quartz cells was used to measure absorbance of the resulting solution.

All chemicals used were of analytical reagent grade and the solvents were spectroscopic grade. Double distilled water was used wherever required.

Pharmaceutical grade tolterodine tartarate was used from two pharmaceutical companies namely Pfizer (as Detrusitol ${ }^{\circledR}$ $4 \mathrm{mg}$ capsules) and Pharmacia and Upjohn S.P.A (as Detrusitol® 2 mg tablets).
The stock solution of $200 \mu \mathrm{g} / \mathrm{mL}$ tolterodine tartrate was prepared in doubly distilled water and was used to prepare different standard solutions.

An aqueous solutions of (methylene blue) (Merck; 100 $\mu \mathrm{g} / \mathrm{mL}$ ) and (indigo) (Aldrich; $200 \mu \mathrm{g} / \mathrm{mL}$ ) and were prepared by dissolving the appropriate weight of the dye in a very small volume of water and then made up to $100 \mathrm{~mL}$ in a calibrated flask.

The stock solutions of dyes were allowed to stand at room temperature for a few weeks without any significant decay. A stock solution of $1.0 \mathrm{mg} / \mathrm{mL} \mathrm{Ce}(\mathrm{IV})$ (Aldrich) was prepared by dissolving the appropriate weight in $0.5 \mathrm{~mol} / \mathrm{L} \mathrm{H}_{2} \mathrm{SO}_{4}$ solution. This solution was then standardized using sodium oxalate and stored in a dark.

A stock solution of $\mathrm{N}$-bromosuccinimide solution (600 $\mu \mathrm{g} / \mathrm{mL}$ ) was prepared by dissolving appropriate amount of in $200 \mathrm{~mL}$ of water the mixture is warmed for $0.5 \mathrm{~h}$ cooled to room temperature then the final volume was adjusted to $250 \mathrm{~mL}$.

\section{Procedures}

Method A: Different volumes of standard tolterodine tartrate solutions were pipette into $10 \mathrm{~mL}$ volumetric flasks, then $0.5 \mathrm{~mL}$ of $\mathrm{Ce}(\mathrm{IV})$ solution was added the mixture was then shacked and kept for $5 \mathrm{~min}$, after that $1.0 \mathrm{~mL}$ of the methylene blue then the solution was made up to the $10.0 \mathrm{~mL}$ with distilled water. The absorbance was then measured at 660 $\mathrm{nm}$ after $10 \mathrm{~min}$.

Method B: The same method above was performed except that $2 \mathrm{~mL}$ N-bromosuccinimide and $0.5 \mathrm{~mL}$ of indigo carmine dye solutions were used, the absorbance of the final solutions were measured at $610 \mathrm{~nm}$.

Assay procedure for drug formulations: An amount of finely ground tablets or capsules equivalent to $2.0 \mathrm{mg}$ of tolterodine tartrate was accurately weighed, dissolved in appropriate amount of distilled water and transferred to a 100$\mathrm{mL}$ volumetric flask, the flask was sonicated for about $20 \mathrm{~min}$, finally the volume was made up to the mark. The content was kept aside for $5 \mathrm{~min}$ and filtered using $0.45 \mu \mathrm{m}$ GHP filter paper. The first $10 \mathrm{~mL}$ portion of the filtrate was discarded and a suitable aliquot was used for the assay as described under general analytical procedure for the proposed method or using HPLC method ${ }^{19}$.

\section{RESULTS AND DISCUSSION}

Tolterodine tartrate undergoes fast oxidation reaction with strong oxidizing agents. It is also shows no absorption band in the visible region which makes it difficult to be determined directly using simple spectrophotometric methods. So we suggest two simple and inexpensive procedures for the determination of tolterodine tartrate in pure and pharmaceutical preparations based on treating tolterodine tartrate solutions with an excess amount of oxidizing agent, then the residual amount of oxidant bleaches certain dye, so that the remaining amount of dye can be determined spectrophotometrically. As a result, a proportional increase in the absorbance for the two dyes is observed with increasing concentration of tolterodine tartrate.

In method A. Ce(IV) in sulfuric acid was used as oxidizing agent and (methylene blue) was used as a dye, the absorbance was measured at $610 \mathrm{~nm}$. In method B. N-bromosuccinimide 
in aqueous medium was used as oxidizing agent and (indigo) was used as the dye which has an absorption maxima at $660 \mathrm{~nm}$.

Preliminary experiments were performed to fix the upper concentrations of the dyes that could be determined spectrophotometrically and these were found to be 20 and $40 \mu \mathrm{g} / \mathrm{mL}$ for (methylene blue) and (indigo), respectively.

A Ce(IV) concentration of $8.0 \mu \mathrm{g} / \mathrm{mL}$ was found to bleach the red colour due to $5 \mu \mathrm{g} / \mathrm{mL}$ of methylene blue whereas 34.0 $\mu \mathrm{g} / \mathrm{mL} \mathrm{N}$-bromosuccinimide was required to destroy the blue colour due to $10 \mu \mathrm{g} / \mathrm{mL}$ of indigo.

For both methods the absorbance was monitored with time which showed that the oxidation reaction is fast and complete in $5 \mathrm{~min}$ and contact times up to $0.5 \mathrm{~h}$ had no effect on the absorbance of dyes.

Optimization of the parameters: The optimum conditions for colour development in each method were established by varying the parameters one at a time, keeping the others fixed and observing the effect produced on the absorbance of the coloured species for methods $\mathbf{A}$ and $\mathbf{B}$. In a series of experiments, the volumes of both oxidant solutions was varied using the constant concentrations of both tolterodine tartrate and the selected dyes, the results which are shown in Figs. 2 and 3 revealed that the optimum volumes of both $\mathrm{Ce}$ (IV) and $\mathrm{N}$-bromosuccinimide oxidants was 1 and $2 \mathrm{~mL}$ of the given concentrations, respectively. In order to choose the suitable dye volumes, the absorbance values were measured at the corresponding wavelengths at constant tolterodine tartrate and oxidant concentrations as shown in Figs. 4 and 5. For methods $\mathbf{A}$ and $\mathbf{B}$ the effect of time on the absorbance values were investigated, the obtained results show no appreciable change after $5 \mathrm{~min}$, so it decided to measure the absorbance after 10 min from preparing the mixtures.

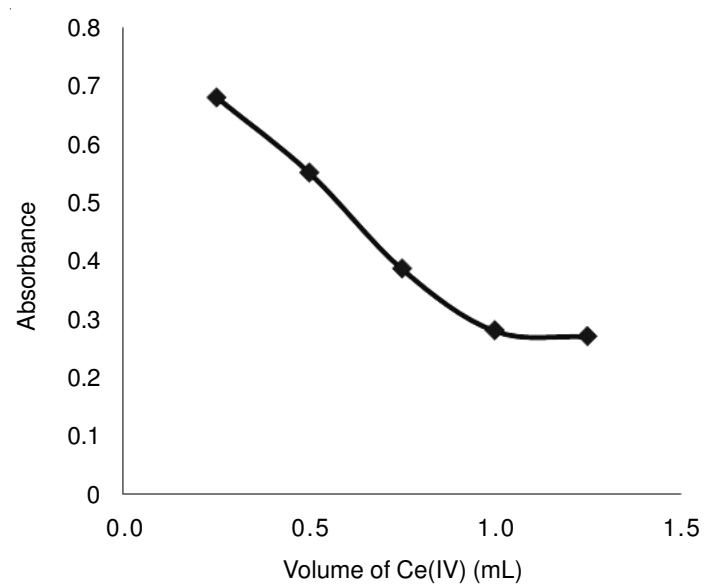

Fig. 2. Effect of variation of volume of $1.0 \mathrm{mg} / \mathrm{mL}$ of Ce(IV) solutions on the absorbance measured at $660 \mathrm{~nm}$. using $1 \mathrm{~mL}$ of $100 \mu \mathrm{g} / \mathrm{mL}$ of methylene blue and $0.5 \mathrm{~mL}$ of $200 \mu \mathrm{g} / \mathrm{mL}$ of tolterodine tartrate in $10.0 \mathrm{~mL}$ volumetric flasks (method $\mathbf{A})$

\section{Method validation}

Analytical parameters: Calibration curves for tolterodine tartrate determination using the proposed methods $\mathbf{A}$ and $\mathbf{B}$ were constructed by plotting absorbance versus concentration using the optimized amounts of oxidants and dyes. The intercepts,

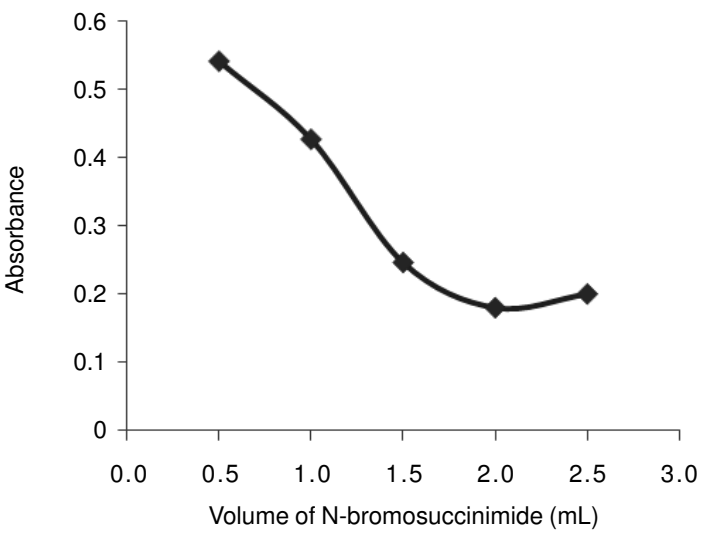

Fig. 3. Effect of variation of volume of $0.6 \mathrm{mg} / \mathrm{mL}$ of $\mathrm{N}$-bromosuccinimide solutions on absorbance measured at $610 \mathrm{~nm}$ using $0.5 \mathrm{~mL}$ of 200 $\mu \mathrm{g} / \mathrm{mL}$ of Indigo and $3 \mathrm{~mL}$ of $200 \mu \mathrm{g} / \mathrm{mL}$ of tolterodine tartrate in $10.0 \mathrm{~mL}$ volumetric flasks $(\operatorname{method} \mathbf{B})$

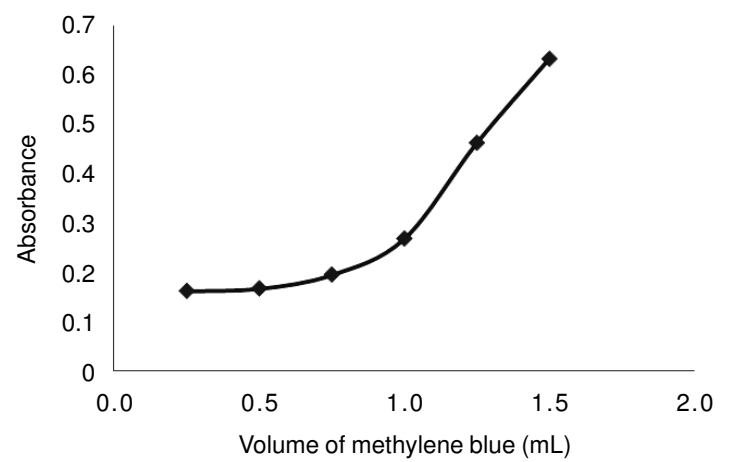

Fig. 4. Effect of variation the volume of $100 \mu \mathrm{g} / \mathrm{mL}$ (methylene blue) on absorbance measured at $660 \mathrm{~nm}$. Using $1 \mathrm{~mL}$ of $1.0 \mathrm{mg} / \mathrm{mL}$ of $\mathrm{Ce}(\mathrm{IV})$ solution and $0.5 \mathrm{~mL}$ of $200 \mu \mathrm{g} / \mathrm{mL}$ of tolterodine tartrate in $10.0 \mathrm{~mL}$ volumetric flasks $(\operatorname{method} \mathbf{A})$

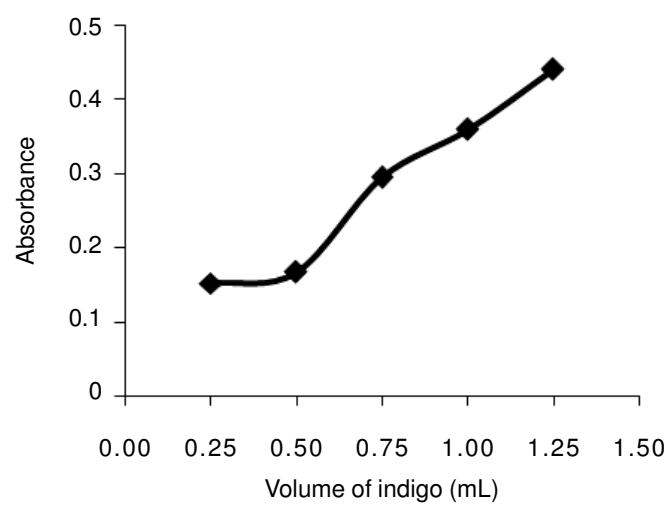

Fig. 5. Effect of variation of volume of $600 \mu \mathrm{g} / \mathrm{mL}$ of (indigo) dye on absorbance measured at $610 \mathrm{~nm}$. Using $2 \mathrm{~mL}$ of $0.6 \mathrm{mg} / \mathrm{mL}$ of $\mathrm{N}$ bromosuccinimide solutions and $3 \mathrm{~mL}$ of $200 \mu \mathrm{g} / \mathrm{mL}$ of tolterodine tartrate in $10.0 \mathrm{~mL}$ volumetric flasks (method B).

slopes and correlation coefficients were calculated using the method of least squares. Beer's law is obeyed over concentration ranges of $3-18 \mu \mathrm{g} / \mathrm{mL}$ for (method $\mathbf{A}$ ) and $38-80 \mu \mathrm{g} / \mathrm{mL}$ for (method B). The mean molar absorptivity $(\varepsilon)$, limit of detection $(\mathrm{LOD}=3 \mathrm{~s} / \mathrm{k})$ and limit of quantitation $(\mathrm{LOQ}=10 \mathrm{~s} / \mathrm{k})$ were calculated, where $\mathrm{s}$ is the standard deviation of replicate determinations in the absence of analyte under the same conditions as sample analysis and $\mathrm{k}$ is the slope. The LOD were 1.5 and $12 \mu \mathrm{g} / \mathrm{mL}$ using methods $\mathbf{A}$ and $\mathbf{B}$, respectively, these statistical results are shown in Table-1. 
TABLE-2

COMPARISON BETWEEN THE PROPOSED METHOD AND STANDARD METHOD

\begin{tabular}{|c|c|c|c|c|c|}
\hline \multirow{2}{*}{ Durg } & \multicolumn{2}{|c|}{ Proposed method } & \multicolumn{3}{|c|}{ Standard method } \\
\hline & Amount taken $(\mu \mathrm{g} / \mathrm{mL})$ & Recovery \pm RSD $(\%)$ & Amount taken $(\mu \mathrm{g} / \mathrm{mL})$ & Recovery $\pm \operatorname{RSD}(\%)$ & $t$-Value \\
\hline Method A & 15 & $97 \% \pm 8$ & 15 & $98 \% \pm 2$ & 0.85 \\
\hline Method B & 50 & $98 \% \pm 8$ & 50 & $97 \% \pm 2$ & 0.56 \\
\hline
\end{tabular}

TABLE-1

STATISTICAL ANALYSIS OF CALIBRATION GRAPHS AND ANALYTICAL DATA FOR THE DETERMINATION OF TOLTERODINE TARTATE USING THE PROPOSED METHODS

\begin{tabular}{lcc}
\hline \multirow{2}{*}{ Parameters } & \multicolumn{2}{c}{ Proposed method } \\
\cline { 2 - 3 } & R & B \\
\hline Wavelengths $\lambda_{\max }(\mathrm{nm})$ & 660 & 610 \\
\hline \multicolumn{2}{c}{ Regression equation } \\
\hline Slope $(\mathrm{b})$ & 0.0363 & 0.0025 \\
Intercept $(\mathrm{a})$ & 0.171 & 0.173 \\
Correlation coefficient $(\mathrm{r})$ & 0.995 & 0.996 \\
Beer's law limits $(\mu \mathrm{g} / \mathrm{mL})$ & $5-18$ & $38-80$ \\
Sandell's sensitivity $(\mu \mathrm{g} / \mathrm{mL})$ & 0.0275 & 0.402 \\
LOD $(\mu \mathrm{g} / \mathrm{mL})$ & 1.45 & 12.0 \\
LOQ $(\mu \mathrm{g} / \mathrm{mL})$ & 4.8 & 40.0 \\
RSD $(\%)$ & 0.773 & 1.3655 \\
\hline
\end{tabular}

Application to drug formulation: Statistical comparison of the accuracy and precision of the proposed methods with an HPLC method ${ }^{19}$ was performed using Student's $t$-tests at a $95 \%$ confidence level. The $t$-values did not exceed the theoretical values; there is no significant difference in accuracy or precision between the proposed and the official method as shown in Table-2.

\section{Conclusion}

Tolterodine tartrate was determined in a two simple spectrophotometric methods that based on oxidation the drug by $\mathrm{Ce}(\mathrm{IV})$ and $\mathrm{N}$-bromosuccinimide oxidant in the presence of methylene blue and indigo carmine dyes, respectively. The methods were simple, rapid, accurate and they were validated and compared to standard methods.

\section{ACKNOWLEDGEMENTS}

The financial support of University of Jordan is duly acknowledged.

\section{REFERENCES}

1. B.K. Malhotra, P. Glue, K. Sweeney, R. Anziano, J. Mancuso and P. Wicker, Clin. Pharmacol. Therap., 81, 377 (2007).

2. L. Palmer, L. Andersson and T. Stenberg, J. Pharm. Biomed. Anal., 16, 155 (1997).

3. R. Swart, P. Koivisto and K.E. Markides, J. Chromatogr. A, 828, 209 (1998).

4. R. Swart, P. Koivisto and K.E. Markides, J. Chromatogr. B: Biomed. Sci. Appl., 736, 247 (1999).

5. Z. Beibei, Z. Zunjian, T. Yuan and X. Fengguo, J. Chromatogr. B: Anal. Technol. Biomed. Life Sci., 82, 492 (2005).

6. T. Bjorkman, P. Edlund and S. Jacobsson, Anal. Chim. Acta, 468, 263 (2002).

7. M. Jan, P. Pavel and K. Josef, J. Chromatogr. B: Anal. Technol. Biomed. Life Sci., 877, 968 (2009).

8. R. Tore, J. Chromatogr. A, 1127, 286 (2006).

9. Z. Lili, Th. Richard, S. Sherry, E. Dean and W. Jean, J. Pharm. Biomed. Anal., 27, 541 (2001).

10. K.Y. Ravindra, G. Ramulu, V. Vevakanand, V. Gopal, S. Keesari, K.M. Kishore, K. Mukkanti, K. Reddy, M. Satyanarayana, S. Venkatraman and M.A. Suryanarayana, J. Pharm. Biomed. Anal., 35, 1279 (2004).

11. Z. Xia, Zh. Chen and T. Yao, Pharmazie, 62, 170 (2007).

12. R. Nanda, J. Gaikwad and A. Prakash, Res. J. Pharm. Technol., 23, 12 (2009).

13. R. Nanda, J. Gaikwad and A. Prakash, Int. J. Pharm. Technol. Res., 1, 420 (2009).

14. D. Sankar, B. Gowri, R. Durvasa, P. Latha and M. Krishna, Asian J. Chem., 19, 1616 (2007).

15. D. Sankar, D. Kumar, M. Krishna and P. Latha, Asian J. Chem., 17, 1357 (2005).

16. D.G. Sankar, M.V. Krishna, D.V. Kumar and P.V. Latha, Asian J. Chem., 17, 2028 (2005).

17. A. Madhavi, G.S. Reddy, M.V. Suryanarayana and A. Naidu, Chromatographia, 68, 399 (2008).

18. V.S. Dwibhashyam, P. Keerthi, J.V. Ratna and A. Nagappa, J. Pharm. Sci. Technol., 63, 234 (2009).

19. V. Saxena, Z. Zaheer and M. Farooqui, Indian J. Chem. Technol., 13, 242 (2006) 